\title{
EFEITO DO AIB E DO ÁCIDO BÓRICO NA FORMAÇÃO E ENRAIZAMENTO DE BROTOS LATERAIS EM ESTACAS DE ORQUÍDEAS
}

\author{
MENGARDA, Liana Hilda Golin ${ }^{1}$ \\ LOPES, José Carlos ${ }^{2}$ \\ SOUZA, Fabiana Baleeiro Coelho ${ }^{3}$ \\ FREITAS, Allan Rocha de ${ }^{1}$
}

\begin{abstract}
RESUMO: Objetivou-se avaliar o efeito do AIB e do ácido bórico na formação e no enraizamento de brotos em estacas das orquídeas Arundina bambusifolia, Dendrobium nobile, e Oncidium sp. Após sofrerem assepsia em hipoclorito de sódio $1 \%$ por 1 minuto, e enxágüe em água destilada, as estacas foram imersas por 1 min em diferentes concentrações de $\operatorname{AIB}\left(0,400,800,1200 \mathrm{mg} \mathrm{mL}^{-1}\right)$, associado ou não ao tratamento prévio com ácido bórico $\left(100 \mathrm{ug} \mathrm{mL} \mathrm{mL}^{-1}\right)$. As estacas foram dispostas em tubetes contendo substrato comercial, mantidos em casa de vegetação com nebulização. A avaliação da porcentagem de brotação, enraizamento, sobrevivência, número e comprimento dos brotos e raízes foram realizados aos 90 dias. O pré-tratamento com ácido bórico induziu a maior porcentagem de mortalidade e menor enraizamento, não sendo indicado na propagação por estaquia das orquídeas em estudo. Sem tratamento com ácido bórico, para A. bambusifolia, a concetração de $400 \mathrm{mg} \mathrm{L}^{-1}$ de AIB promoveu maior porcentagem de brotação e maior comprimento dos brotos. Para $D$. nobile as melhores respostas quanto às brotações foram obtidas sem nenhum tratamento, enquanto a concentração de $1200 \mathrm{mg} \mathrm{L}^{-1}$ de AIB promoveu maior enraizamento. Oncidium sp. não respondeu adequadamente a propagação por estaquia.
\end{abstract}

Palavras-chave: Arundina bambusifolia. Dendrobium nobile. Oncidium sp. Propagação. Auxina.

\section{IBA AND BORIC ACID EFFECT IN THE FORMATION AND ROOTING OF LATERAL SHOOTS IN CUTTINGS OF ORCHIDS}

SUMMARY: The objective of this study was to evaluate the IBA and boric acid application effect in the formation and rooting of shoots from cuttings in Arundina bambusifolia, Dendrobium nobile, and Oncidium sp. After sterilization in $1 \%$ sodium hypochlorite for $1 \mathrm{~min}$, and rinse in distilled water, the cuttings were immersed for $1 \mathrm{~min}$ at different IBA concentrations $\left(0,400,800,1200 \mathrm{mg} \mathrm{L}^{-1}\right)$, with or no previous treatment with boric acid $(100 \mu \mathrm{g}$ $\left.\mathrm{mL}^{-1}\right)$. The cuttings were placed in tubes containing a commercial substrate, packed in trays in a greenhouse with intermittent mist. The evaluation of sprouting, rooting, survival, number and length of shoots and roots was performed at 90 days. The use of boric acid induced higher mortality and lower rooting, not indicated its use in propagation by cuttings of these orchids. Without treatment with boric acid to A. bambusifolia, $400 \mathrm{mg} \mathrm{L}^{-1}$ of IBA promoted highest sprouting and increased shoot length. To D. nobile better answers about the shoots were obtained without any treatment, while the concentration of $1200 \mathrm{mg} \mathrm{L}^{-1}$ IBA promoted higher rooting percentage. Oncidium sp. not respond adequately to cutting propagation.

Keywords: Arundina bambusifolia. Dendrobium nobile. Oncidium sp. Propagation. Auxin.

\section{INTRODUÇÃO}

Arundina bambusifolia, também conhecida como orquídea-bambu, apresenta caule juncoso, formando grandes massas que crescem até uma altura de $2 \mathrm{~m}$. As flores se formam no verão e apresentam uma tonalidade lilás rosada com o labelo púrpura. O gênero é, em geral, de orquídeas terrestres bastante

\footnotetext{
${ }^{1}$ Programa de Pós-graduação em Produção Vegetal - Universidade Federal do Espírito Santo

${ }^{2}$ Departamento de Produção Vegetal - Universidade Federal do Espírito Santo

${ }^{3}$ Programa de Pós-graduação em Ciências Florestais - Universidade Federal do Espírito Santo
} 
rústicas. Dendrobium nobilde, conhecida como olho-de-boneca, é a mais popular de todas as orquídeas, e também a que apresenta maior rusticidade e facilidade de cultivo (PATRO, 2011). Além do largo cultivo, esta espécie vem sendo muito utilizada para hibridização de orquídeas (MORAES, 2002). A coloração das flores pode variar muito; a mais comum é a branca com as extremidades rosadas e o labelo com o centro arroxeado bem escuro. Seus pseudobulbos apresentam coloração verde clara a amarelada. Oncídio ou chuva-de-ouro, são nomes populares dados ao grupo de orquídeas pertencentes ao gênero Oncidium. A principal característica deste gênero é a presença de um calo situado na base do labelo da flor. As flores geralmente são amarelas, marrons, verdes, alaranjadas ou tigradas. Apresentam hábito epifítico, seus pseudobulbos são ovalados e achatados e contém duas ou quatro folhas cada (PATRO, 2011).

A produção comercial de mudas de orquídea geralmente é feita por clonagem ou pela separação dos pseudobulbos das touceiras originadas de uma planta matriz, com posterior brotação e enraizamento para formação de mudas. Tal produção, também chamada de estaquia, diminui gastos com uso de técnicas de laboratório tornando-a mais viável para pequenos produtores, além de aumentar o retorno financeiro (VILELA et al., 2010). Neste processo, ao cortar o pseudobulbo entre um nó e outro, os brotos laterais se formam a partir desses nós formando novas mudas.

Contudo, a obtenção de plantas por estaquia é um processo lento e impraticável para algumas espécies que não possuem a composição química endógena necessária à indução da formação de raízes (FERREIRA et al., 2009). A formação de raízes em estacas é um processo anatômico e fisiológico complexo, associado à desdiferenciação e ao redirecionamento do desenvolvimento de células vegetais totipotentes para a formação de meristemas que darão origem a raízes adventícias. $\mathrm{O}$ enraizamento de estacas pode ser influenciado por injúrias, pelo balanço hormonal, pela constituição genética, pela presença de inibidores e pelas condições nutricionais e hídricas da planta doadora de propágulos, além de ser fortemente influenciado pela maturação e juvenilidade dos propágulos e pelas condições ambientais (ASSIS et al., 2004; WENDLING; XAVIER, 2005; BORGES et al., 2011).

Assim, o enraizamento no processo de propagação por estaquia, é um processo crítico que, geralmente, requer estudos acerca do emprego de reguladores vegetais, especificamente do grupo das auxinas, e de cofatores do enraizamento, que, além de estimularem e acelerarem o enraizamento das estacas uniformiza e induz a formação de raízes em plantas tidas como de difícil enraizamento (ONO et al., 1994).

Os cofatores do enraizamento são substâncias capazes de atuar sinérgicamente com a auxina endógena no enraizamento de estacas. Esses cofatores podem ser compostos fenólicos, compostos do triazol, carboidratos, boro, e outros. Com relação a aplicação de auxina exógena, é muito comum o emprego do ácido indolbutírico (AIB) que, em contato com as estacas eleva a relação auxina e citocinina no interior da planta, acarretando uma série de transformações fisiológicas e morfológicas ao desenvolvimento (HARTMANN et al., 2002). O AIB, entre as demais auxinas sintéticas, apresenta menor mobilidade e maior estabilidade química no interior da estaca, e, assim, apresenta alta atividade, faixa maior de concentrações não fitotóxicas e pode ser efetiva em muitas espécies (PIRES; BIASI, 2003).

Os estudos com propagação via estaquia em orquídeas evidenciam o sucesso deste método principalmente com baunilia (Vanilla planifolia) (SILVA et al., 2009) já sendo utilizado em nível comercial. No entanto, poucos estudos descrevem a aplicação desta técnica em outras espécies de Orchidaceaes. Assim, este trabalho objetiva verificar os efeitos da aplicação de AIB e ácido bórico na indução de brotos laterais e seu enraizamento, a partir do processo de estaquia das orquídeas Arundina bambusifolia, Dendrobium nobile, e Oncidium sp. 


\section{MATERIAL E MÉTODOS}

O trabalho foi desenvolvido em casa de vegetação do Departamento de Produção Vegetal / Centro de Ciências Agrárias da Universidade Federal do Espírito Santo (CCA-UFES), em Alegre, ES, situada na

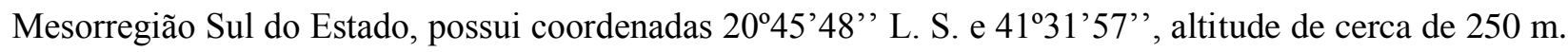
O clima predominante é quente úmido no verão, e seco no inverno, com precipitação anual média de 1200 $\mathrm{mm}$, temperatura média em torno de $23{ }^{\circ} \mathrm{C}$. Nos meses em que transcorreram as avaliações do experimento, a temperatura média (T), a umidade relativa média (UR\%) e a precipitação média mensal (PMM) foram: setembro 2011: $\mathrm{TM}=21.3{ }^{\circ} \mathrm{C}, \mathrm{UR}=62 \%$ e $\mathrm{PMM}=10,9 \mathrm{~mm}$; outubro 2011 : $\mathrm{TM}=22.9^{\circ} \mathrm{C}$, $\mathrm{UR}=67 \%$ e $\mathrm{PMM}=55,83 \mathrm{~mm}$; e novembro de $2011=\mathrm{TM}=22.5^{\circ} \mathrm{C}, \mathrm{UR}=67 \%$ e $\mathrm{PMM}=86.4 \mathrm{~mm}$.

As estacas foram obtidas a partir de plantas matrizes cultivadas na casa de vegetação do Departamento de Produção Vegetal - CCA - UFES. Estas foram confeccionadas tendo como padronização o número de nós (dois nós para A. bambusifolia e D. nobile e três nós para Oncidium sp.), e a base seccionada em corte reto. As estacas permaneceram em recipiente com água para evitar a desidratação, e assim, que secionadas, foram submetidas ao tratamento sanitário, constituído de imersão em hipoclorito de sódio $1 \%$ por 1 minuto. Em seguida, as estacas foram lavadas em água corrente por 5 minutos.

Os tratamentos de indução de brotações e enraizamento consistiram na aplicação de diferentes concentrações de $\operatorname{AIB}\left(0,400,800,1200 \mathrm{mg} \mathrm{mL}^{-1}\right)$ por 1 minuto, associado ou não ao tratamento prévio com ácido bórico (100 $\square \mathrm{g} \mathrm{mL}^{-1}$ ) pelo mesmo período. Em seguida, as estacas foram dispostas em tubetes contendo substrato comercial. As estacas foram irrigadas por câmara de nebulização com regime intermitente controlado por temporizador. A válvula de nebulização foi programada para 10 segundos, em intervalos de 15 minutos durante todo o experimento.

As estacas permaneceram em casa de vegetação por um período de 90 dias, quando foram avaliadas a porcentagem de enraizamento (estacas vivas que apresentaram raízes de, no mínimo, $1 \mathrm{~mm}$ de comprimento); porcentagem de brotação (estacas vivas que apresentaram brotos de, no mínimo, $1 \mathrm{~mm}$ de comprimento); porcentagem de sobrevivência (estacas vivas que não apresentaram indução radicial nem formação de brotos); porcentagem de mortalidade (estacas que se encontravam com tecidos necrosados), número e comprimento das raízes, número e comprimento dos brotos.

$\mathrm{O}$ experimento foi conduzido em esquema fatorial $3 \times 2 \times 4$, sendo três espécies (Arundina bambusifolia, Dendrobium nobile, e Oncidium sp.), duas condições de pré-tratamento com solução de ácido bórico (presente ou ausente), e aplicação de AIB em quatro concentrações (0, 400, 800, $1200 \mathrm{mg}$ $\mathrm{mL}^{-1}$ ), num delineamento inteiramente casualizado (DIC), com 24 tratamentos e quatro repetições. Não sendo verificada interação significativa entre os fatores, procedeu-se análise de regressão para os dados de cada espécie.

\section{RESULTADOS E DISCUSSÃO}

Em A. bambusifolia o tratamento que induziu maior porcentagem de brotações (19\%) e maior porcentagem de brotos enraizados (67\%) foi sem aplicação de ácido bórico e $400 \mathrm{mg} \mathrm{mL}^{-1}$ de AIB (Figura 1a). Os tratamentos com aplicação de ácido bórico e elevadas concentrações de AIB foram prejudiciais na indução de brotos e raízes, e induziram a mortalidade das estacas (50\% de estacas mortas) (Figura 1). 
Figura 1: a, b: Porcentagem de estacas mortas, vivas, e apresentando brotações. c, d: Porcentagem de brotos enraizado e não enraizados, em estacas de Arundina bambusifolia sem aplicação de ácido bórico (esquerda), e com aplicação de $100 \mathrm{mg} \mathrm{L-1}$
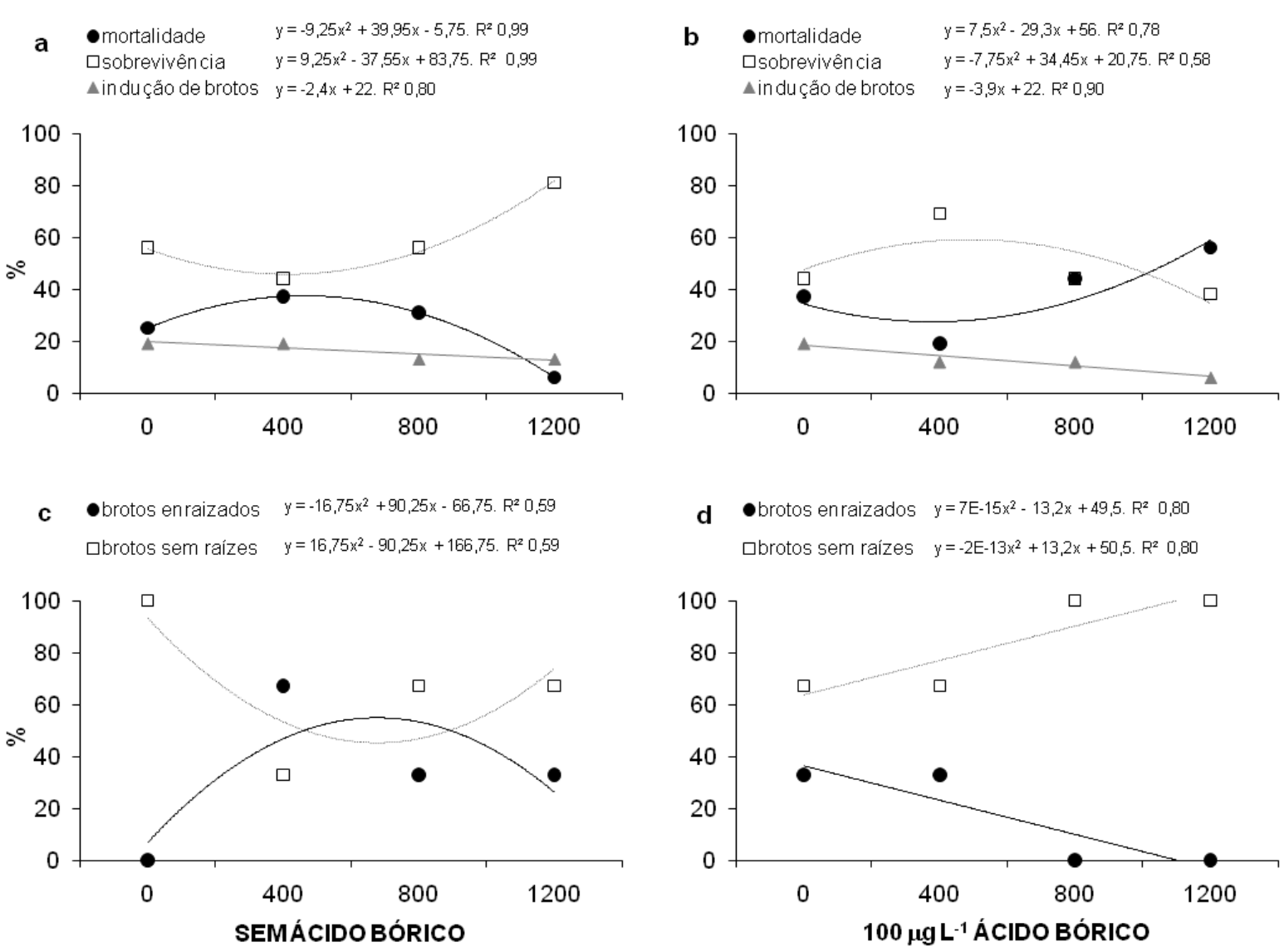

Verifica-se que sem aplicação de ácido bórico, a mortalidade das estacas é reduzida com o aumento da concentração de AIB (Figura 1a) enquanto com o pré-tratamento com ácido bórico, a mortalidade aumenta com a elevação das concentrações de AIB (Figura 1b).

Sem aplicação de ácido bórico, a porcentagem de brotos enraizados foi maior no nível $400 \mathrm{mg}$ $\mathrm{mL}^{-1}$ de AIB (Figura 1c). Com o pré-tratamento, concentrações acima de $400 \mathrm{mg} \mathrm{mL}^{-1}$ de AIB não promoveram enraizamento dos brotos em estacas de A. bambusifolia. Verificou-se, ainda, que o tratamento sem aplicação de ácido bórico e $400 \mathrm{mg} \mathrm{mL}^{-1}$ de AIB, proporcionou maior número médio e maior comprimento das brotações (Figura 2). 
Figura 2: a, b: Número médio de brotos e de raízes. c, d: Comprimento médio dos brotos e das raízes, em estacas de Arundina bambusifolia sem ácido bórico (esquerda), e com aplicação de $100 \mathrm{mg} \mathrm{L}-1$ de ácido bórico (direita); tratadas com 0, 400, 800 e 1200 mg mL-1 de AIB, após 90 dias.
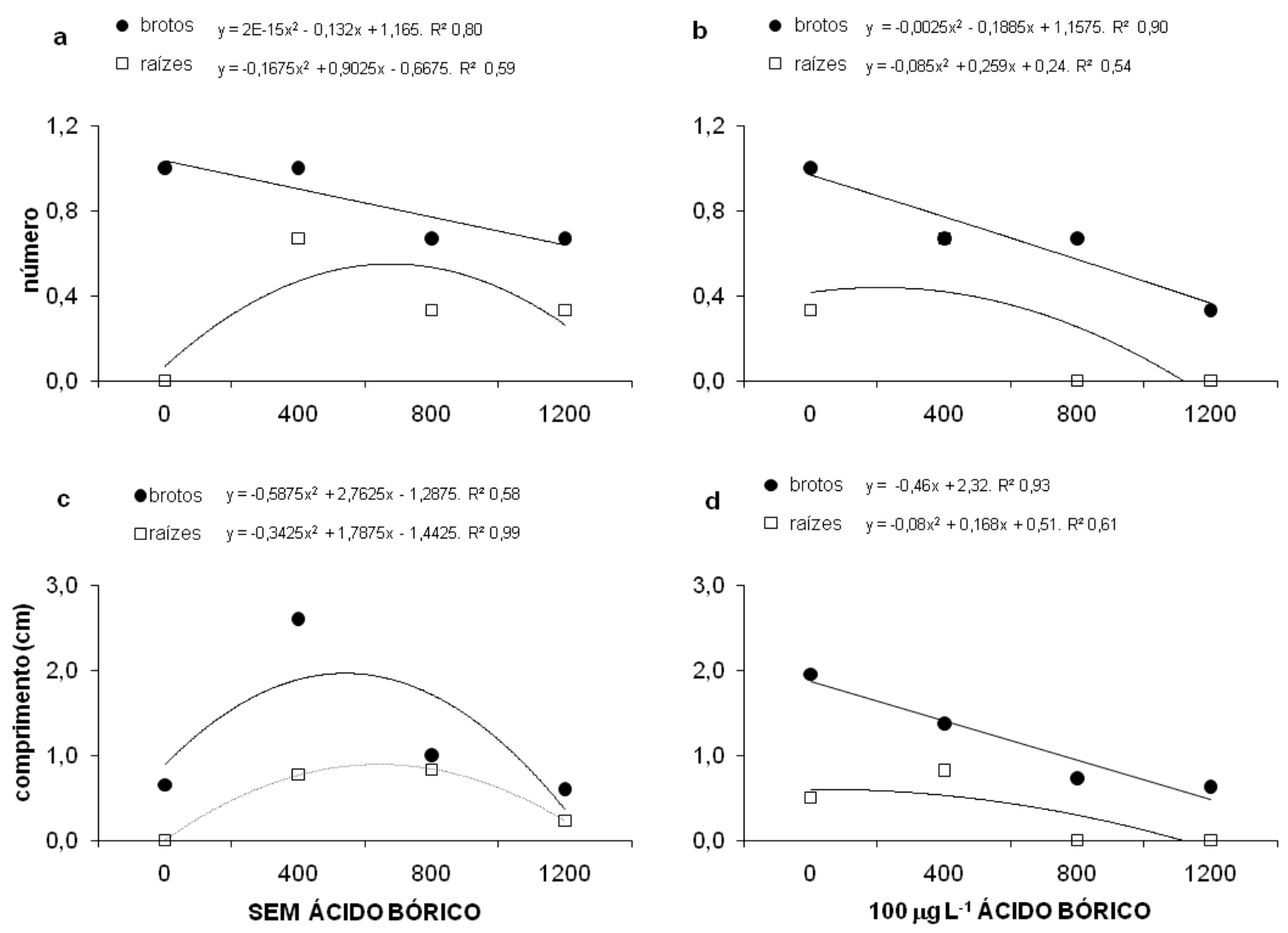

Desta forma, a aplicação de ácido bórico antes do tratamento com AIB é prejudicial, provocando um efeito contrário ao desejado, ou seja, induzindo menor porcentagem de brotações, menor enraizamento e maior mortalidade das estacas de Arundina bambusifolia. Althaus et al. (2007) verificaram que a utilização de ácido bórico não são eficientes para o processo de enraizamento de jasmim. Salibe et al. (2010) constataram que o ácido bórico causou poucos efeitos sobre as variáveis relacionadas ao enraizamento de videira, e sua aplicação em altas concentrações desfavoreceu o acúmulo de massa na parte aérea das estacas. A aplicação de AIB, por sua vez, induziu incremento do enraizamento. Em outros casos, a aplicação de AIB no enraizamento de videira é dispensável (LONE et al., 2010).

Grande número de fatores, de natureza endógena e exógena, afeta a iniciação e o desenvolvimento de raízes. Embora não sejam consideradas espécies de fácil enraizamento, as orquídeas têm teor endógeno de auxinas elevado e, por conta disto, dependendo da espécie, não é necessária aplicação de auxina exógena para promover o enraizamento. Fatores com o número de nós e posição da coleta da estaca podem ser relevantes, como discutem Vilela et al. (2010). Em Dendrobium nobile, se utilizadas estacas medianas, sem imersão em AIB e estacas contendo dois nós, sem imersão de ANA, proporcionam resultados mais satisfatórios na obtenção de mudas. Em estacas herbáceas, como é o caso das orquídeas, quando retiradas durante o verão, os ramos estão em pleno crescimento e apresentam maiores concentrações de auxinas em relação àquelas que são retiradas no outono e inverno. Isto pode indicar que se o experimento fosse conduzido numa estação mais quente os resultados poderiam ser melhores (ZUFFELLATO- RIBAS; RODRIGUES, 2001). Ainda, o fornecimento exógeno de auxina, em certas 
quantidades, pode promover sutis alterações hormonais nestas plantas, capazes de favorecer ou prejudicar o enraizamento de estacas (RAMOS et al., 2003).

Em Dendrobium nobile, as estacas que não receberam nenhum tratamento (T0), apresentaram menor mortalidade (5\%) e maior porcentagem de brotações (55\%) (Figura 3), assim como maior número médio de brotos e raízes (Figura 4). A aplicação de ácido bórico proporcionou maior porcentagem de mortalidade das estacas, e porcentagem reduzida de brotações, assim como número reduzido de brotações enraizadas (menos de $13 \%$ de brotações enraizadas).

Figura 3: a, b: Porcentagem de estacas mortas, vivas, e apresentando brotações. c, d: Porcentagem de brotos enraizado e não enraizados, em estacas de Dendrobium nobile sem aplicação de ácido bórico (esquerda), e com aplicação de $100 \mathrm{mg} \mathrm{L-1}$ de ácido bórico (direita), e com aplicação de 0, 400, 800 e $1200 \mathrm{mg}$ mL-1 de AIB, após 90 dias.
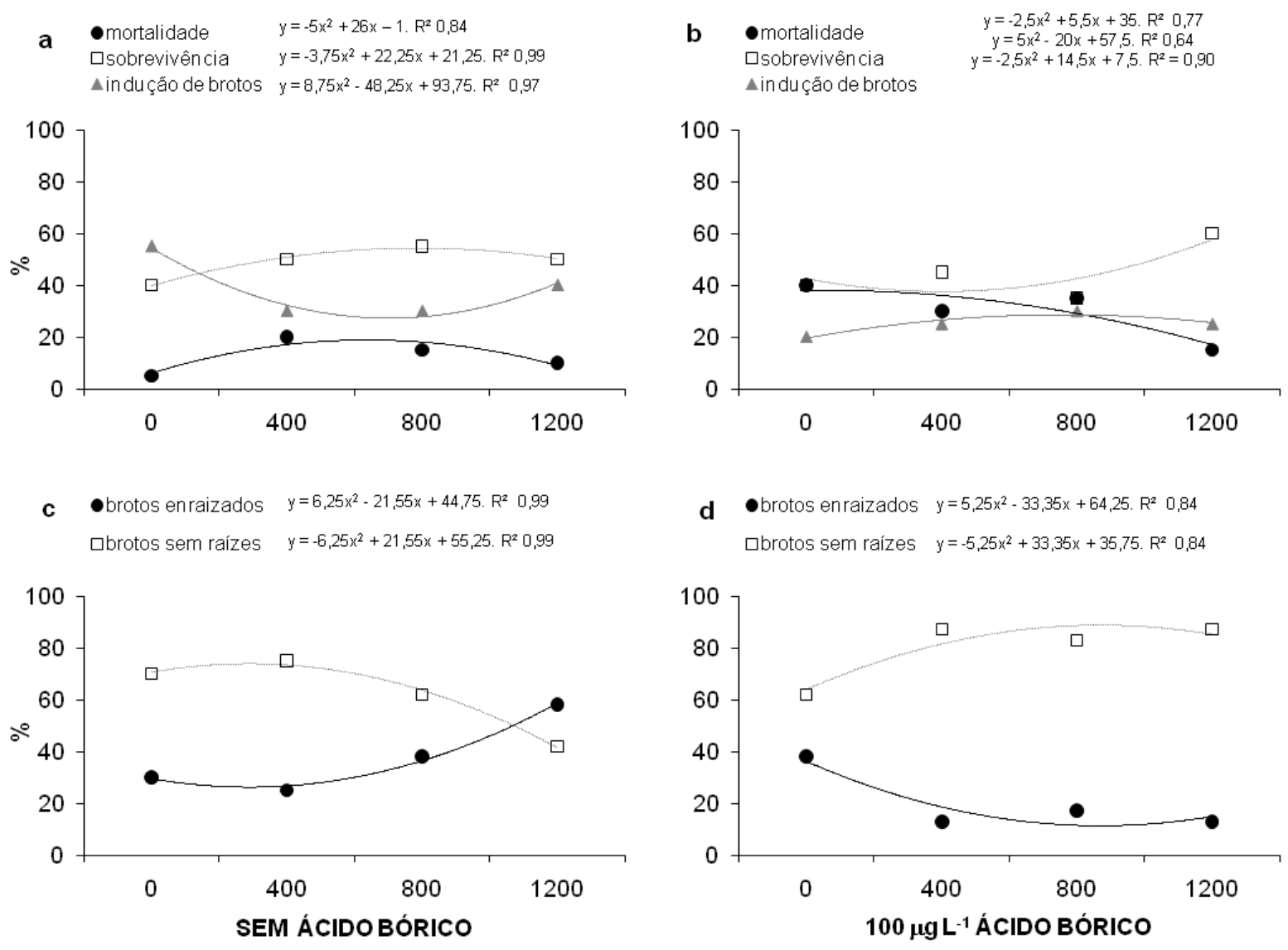
Figura 4: a, b: Número médio de brotos e de raízes. c, d: Comprimento médio dos brotos e das raízes, em estacas de Dendrobium nobile sem ácido bórico (esquerda), e com aplicação de $100 \mathrm{mg}$ L-1 de ácido bórico (direita); tratadas com 0, 400, 800 e 1200 mg mL-1 de AIB, após 90 dias.
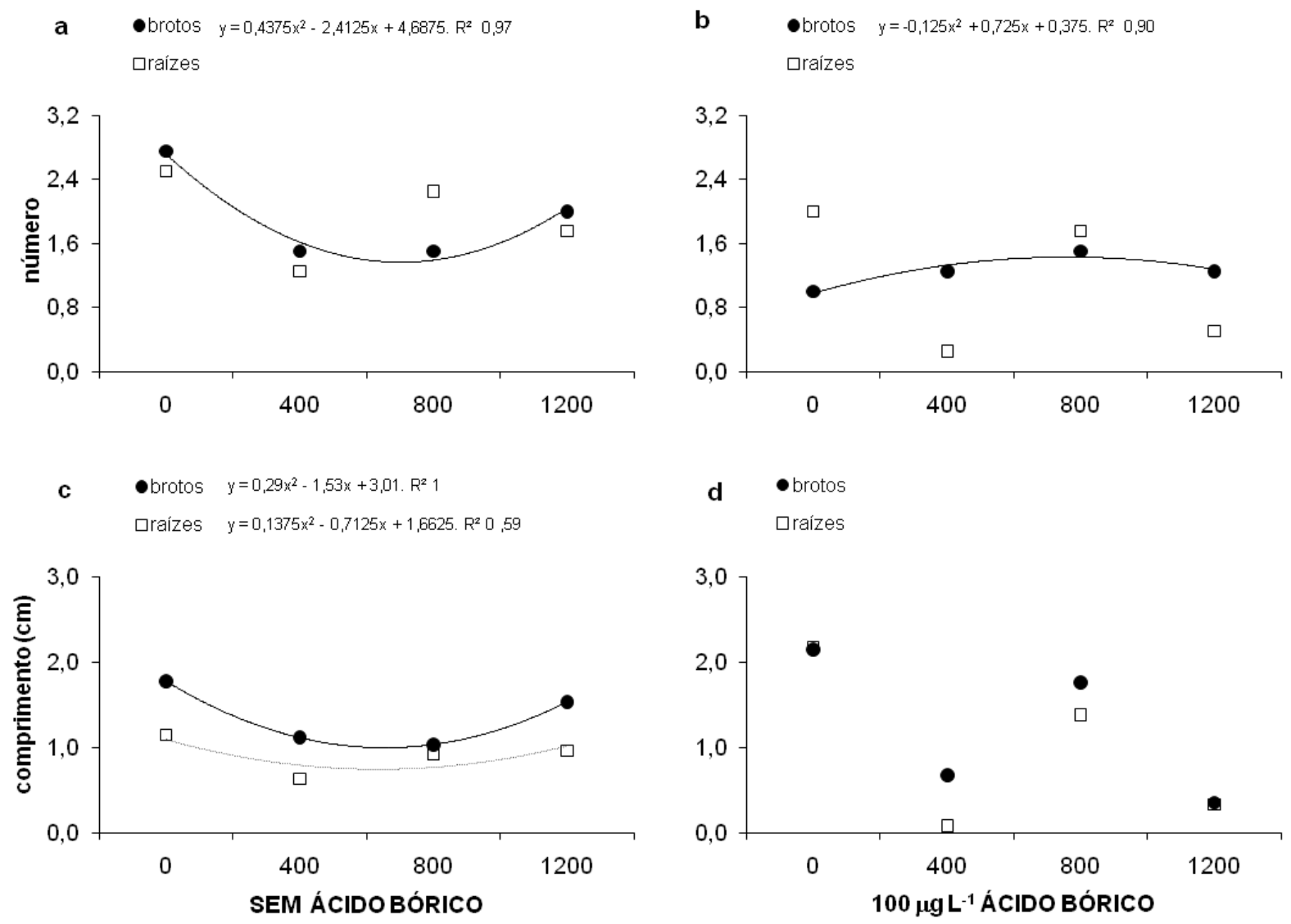

O tratamento com ácido bórico e $1200 \mathrm{mg} \mathrm{mL}^{-1}$ de AIB foi o que apresentou menor comprimento das raízes e dos brotos, e menor número médio de raízes (Figura 4b, d). Por sua vez, esta mesma concentração de AIB, no tratamento sem ácido bórico, induziu maior porcentagem de brotos enraizados (58\%) (Figura 3c), sem comprometimento quando ao número e comprimento médio das raízes (Figura 4a, c).

Embora as estacas não tratadas tenham apresentado maior porcentagem de brotações, o tratamento com $1200 \mathrm{mg} \mathrm{mL}^{-1}$ de AIB proporcionou maior porcentagem de estacas enraizadas, desde que não tratadas previamente com ácido bórico. Com o pré-tratamento com ácido bórico, por sua vez, a reposta é inversa, havendo a redução da porcentagem de enraizamento, com o aumento da concentração de AIB. Nesta condição ainda verifica-se a redução do número médio de raízes, e redução do comprimento médio dos brotos e raízes (Figura 4d). Assim, da mesma forma como para A. bambusifolia, a aplicação de ácido bórico em estacas de $D$. nobile não é recomendada.

Oncidium sp. apresentou valores reduzidos quando a brotações e enraizamento das estacas, quando comparada as demais espécies em estudo. Embora a maioria das estacas tenham sobrevivido, os tratamentos mais eficientes promoveram brotações em cerca de $10 \%$ das estacas. Dos brotos formados, apenas dois tratamentos mostraram-se capazes de formar raízes. Estacas não tratadas e tratadas apenas com ácido bórico (sem AIB), não apresentaram nenhuma brotação. Sem ácido bórico e com elevada concentração de AIB, também apresentou resposta negativa quando a brotações (Figura 5). 
Figura 5: a, b: Porcentagem de estacas mortas, vivas, e apresentando brotações. c, d: Porcentagem de brotos enraizado e não enraizados, em estacas de Oncidium sp. sem aplicação de ácido bórico (esquerda), e com aplicação de 100 mg L-1 de ácido bórico (direita), e com aplicação de 0, 400, 800 e 1200 mg mL-1 de AIB, após 90 dias.
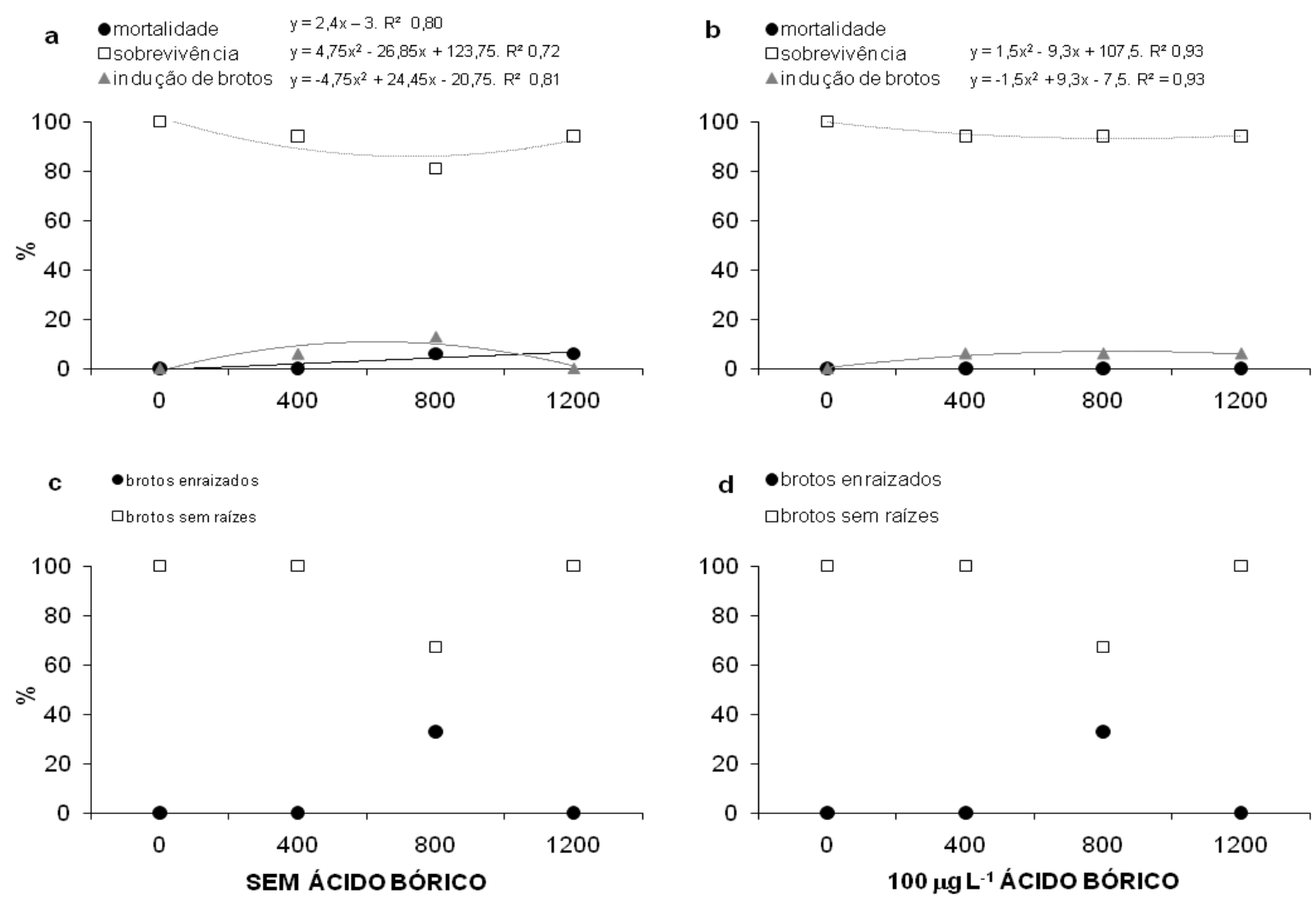

d brotos en raizados

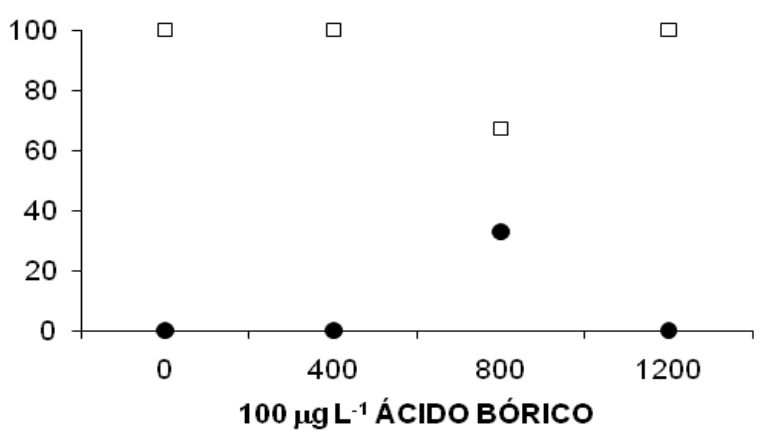

A concentração de $800 \mathrm{mg} \mathrm{mL}^{-1}$ de AIB, independente da aplicação de ácido bórico, parece apresentar melhor resultado na propagação de Oncidium sp. via estaquia (Figuras 5 e 6). 
Figura 6: a, b: Número médio de brotos e de raízes. c, d: Comprimento médio dos brotos e das raízes, em estacas de Oncidium sp. sem ácido bórico (esquerda), e com aplicação de $100 \mathrm{mg} \mathrm{L-1}$ de ácido bórico (direita); tratadas com 0, 400, 800 e $1200 \mathrm{mg} \mathrm{mL-1} \mathrm{de} \mathrm{AIB,} \mathrm{após} 90$ dias.
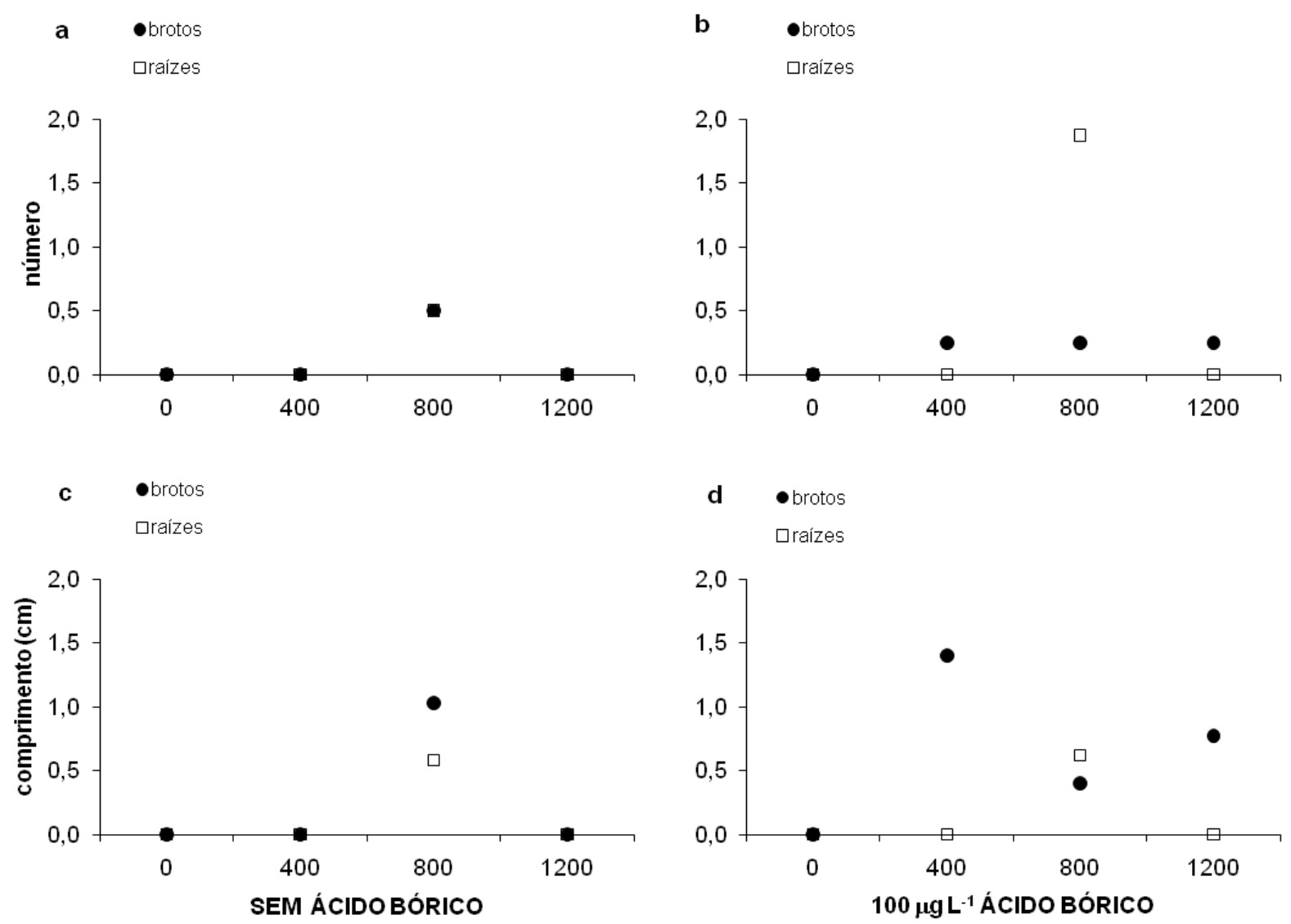

Para o gênero Oncidium, o tipo e a concentração da fonte de carbono são importantes para promover o desenvolvimento das plântulas das orquídeas in vitro (REGO-OLIVEIRA et al., 2003). Durante aclimatação, a pulverização com auxina resulta em maior enraizamento e desenvolvimento vegetativo, sendo mais efetiva do que a imersão rápida das plântulas em solução de auxina (SORACE $e t$ al., 2009). Assim, a ação pouco representativa da auxina pode ser decorrente da forma de aplicação desta.

Baunília é uma das espécies de orquídeas mais conhecida e cultivada comercialmente pelo método de estaquia. O procedimento é realizado a partir de estacas caulinares obtidas pelo seccionamento da haste da planta e a porcentagem de enraizamento fica em torno de 98 - 100\%. Mesmo muito estudado, o método de propagação não é considerado econômico, devido à alta taxa de mortalidade das estacas (SILVA et al., 2009), fenômeno também verificado neste estudo com A. bambusifolia, D. nobile, e Oncidium sp.

\section{CONCLUSÃO}

A aplicação de ácido bórico como cofator de enraizamento foi prejudicial, anulando ou interferindo negativamente na ação da auxina aplicada, para as espécies de orquídea estudadas.

A combinação do uso de ácido bórico + AIB em elevadas concentrações induziu a maior mortalidade e menor enraizamento, não sendo indicado seu uso na propagação por estaquia destas orquídeas. 
O uso de AIB sem ácido bórico em A. bambusifolia foi eficiente na concentração de $400 \mathrm{mg} \mathrm{mL}^{-1}$, promovendo maior enraizamento, maior comprimento e número de brotos.

D. nobile apresenta melhores resultados referentes às variáveis avaliadas quando não tratadas com AIB e ácido bórico.

Oncidium apresenta resultados insatisfatórios quanto à propagação por estaquia.

\section{REFERÊNCIAS}

ALTHAUS, M.M. et al. Influência do ácido naftaleno acético e dois tipos de substrato no enraizamento de estacas de jasmim-amarelo. Ciência Agronômica, Fortaleza, v. 38, n. 3, p. 322-326, 2007.

ASSIS, T. F.; FETT-NETO, A. G.; ALFENAS, A. C. Current techniques and prospects for the clonal propagation of hardwoods with emphasis on Eucalyptus. In: WALTER, C.;

CARSON, M. (Eds.). Plantation forest biotechnology for the 21th century. Kerala, India: Research Signpots, 2004. p. 303-333.

FERREIRA, B.G.A. et al. Metodologias de aplicação de AIB no enraizamento de estacas semilenhosas de Sapium glandulatum (Vell.) Pax. Revista Brasileira de Plantas Medicinais, Botucatu, v. 11, n. 2, p. 195200, 2009.

HARTMANN, H.T. et al. Plant propagation: principles and practices. 7.ed. New York: Englewood Clipps, 2002. 880p.

LONE, A.B. et al. Efeito do AIB no enraizamento de estacas herbáceas do porta-enxerto de videira VR 43-43 em diferentes substratos. Semina: Ciências Agrárias, Londrina, v. 31, n. 3, p. 599-604, 2010.

MORAES, L.M.; CAVALCANTE, L.C.D.; FARIA, R.T. Substratos para aclimatização de plântulas de Dendrobium nobile Lindl. (Orchidaceae) propagadas in vitro. Acta Scientiarum, Maringá, v. 24, n. 5, p. 1397-1400, 2002.

ONO, E.O.A.; RODRIGES, J.D.; PINHO, S.Z. Ação de auxinas e/ou boro, no processo de formação de raízes em estacas de café (Coffea arabica L. CV. "Mundo Novo"). Arquivos de Biologia e Tecnologia, Curitiba, v. 37, n. 1, p. 157-66, 1994.

PATRO, R. 2011. Orchidaceae. Disponível em: http://www.jardineiro.net/br. Acesso em 01-09-2012. http://www.jardineiro.net/br/geral/orquideas.php

PIRES, E.J.P.; BIASI, L.A. Propagação da videira. In: POMMER, C.V. (Ed.). Uva: tecnologia da produção, pós-colheita e mercado. Porto Alegre: Cinco Continentes, 2003. p. 295-350.

RAMOS, J. D. et al. Enraizamento de estacas herbáceas de 'Mirabolano' (Prunus cerasifera Ehrn) em diferentes substratos e concentrações de ácido indolbutírico. Revista Brasileira de Fruticultura, Jaboticabal, v. 25, n. 1, p. 189-191, 2003.

REGO-OLIVEIRA, L.V. et al. Influência da fonte e concentração de carboidrato no crescimento vegetativo e enraizamento in vitro de Oncidium varicosum Lindl. (Orchidaceae). Semina: Ciências Agrárias, Londrina, v. 24, n. 2, p. 265-272, 2003.

SALIBE, A.B. et al. Enraizamento de estacas do porta-enxerto de videira 'vr 043-43' submetidas a estratificação, ácido indolbutírico e ácido bórico. Bragantia, Campinas, v. 69, n. 3, p. 617-622, 2010. 
SILVA, M.D.D. et al. Enraizamento de estacas de baunilheiras (Orchidaceae). Semina: Ciências Agrárias, v. 30, n. 1, p. 71-80, 2009.

SORACE, M. et al. Influência de auxina na aclimatização de Oncidium baueri (Orchidaceae). Semina: Ciências Agrárias, Londrina, v. 28, n. 2, p. 195-200, 2007.

VILELA, X.M.S. et al. Tipos de pseudobulbos e número de nós no enraizamento e brotação de Dendrobium nobile. Revista Agrarian, Dourados, v. 3, n. 7, p. 1-7, 2010.

WENDLING, I.; XAVIER, A. Influência do ácido indolbutírico e da miniestaquia seriada no enraizamento e vigor de miniestacas de clones de Eucalyptus grandis. Revista Árvore, Viçosa, v. 29, n. 6, p. 921-930, 2005.

ZUFFELLATO-RIBAS, K.C.; RODRIGUES, J.D. Estaquia: uma abordagem dos principais aspectos fisiológicos. Curitiba: UFPR, 2001. 39p. 
